\title{
SELEKSI PENERIMAAN ASISTEN LABORATORIUM MENGGUNAKAN ALGORITMA AHP PADA AMIK-STIKOM TUNAS BANGSA PEMATANGSIANTAR
}

\author{
Anjar Wanto' ${ }^{1}$, dan Eko Kurniawan² \\ ${ }^{1)}$ Teknik Informatika STIKOM Tunas Bangsa \\ Jln. Sudirman Blok A No. 1, 2, 3 Pematangsiantar, Indonesia \\ 2) Sistem Informasi STMIK Triguna Dharma \\ Jl. Jenderal A.H. Nasution No. 73 Medan, Indonesia \\ e-mail: anjarwanto@amiktunasbangsa.ac.id ${ }^{1)}$,ekokurniawann@gmail.com ${ }^{2}$
}

\begin{abstract}
ABSTRAK
Penelitian ini bertujuan untuk membangun sistem pendukung keputusan yang mempunyai kemampuan menganalisa dalam pemilihan asisten laboratorium menggunakan Algoritma Analytical Hierarchy Process (AHP) pada AMIK-STIKOM Tunas Bangsa pematangsiantar. Karena selama ini belum adanya sistem yang dapat membantu manajemen dalam menentukan calon asisten laboratorium yang layak untuk dipekerjakan. Diharapkan dengan adanya sistem ini dapat membantu pihak Yayasan dalam melakukan penilaian dan dapat dijadikan masukan (Referensi) oleh pihak Yayasan untuk mengambil keputusan dalam menyeleksi calon asisten laboratorium yang layak diterima. Seleksi penerimaan asisten laboratorium menggunakan Algoritma Analytical Hierarchy Process (AHP) ini nantinya dapat menghasilkan alternatif terbaik, dengan kriteria-kriteria yang telah ditentukan berupa wawancara, ujian tertulis, ujian praktek, dan IPK. Sehingga seleksi penerimaan asisten laboratorium dapat berjalan secara tepat dan sesuai dengan yang diharapkan. Sistem ini nantinya akan dibangun menggunakan pemrograman web agar proses seleksi menjadi lebih efektif dan efisien.
\end{abstract}

Kata Kunci: AHP, Asisten Laboratorium, SPK, Seleksi.

\begin{abstract}
AMIK Tunas Bangsa is a growing university in Pematangsiantar. Therefore, there are still many university activities and activities that are constrained by problems. One of them is the problem in the selection of employees by the foundation to occupy the position of Laboratory Assistant. Problems that arise in the selection process of acceptance of laboratory assistant at AMIK Tunas Bangsa Pematangsiantar is the absence of tools that can assist management in determining the appropriate candidate laboratory assistant to be the best. By building a system to support the decision of using AHP Algorithm (Analytical Hierarchy Process) is expected to assist the Foundation in conducting the assessment and can be used as input (Reference) by the Foundation to make decisions in selecting the appropriate laboratory assistant candidate accepted. Selection of laboratory assistant acceptance using Analytical Hierarchy Process (AHP) algorithm can yield the best alternative, with criteria in the form of an interview, written test, practice test, and GPA. So the selection of acceptance of laboratory assistants can run exactly and in accordance with the expected.
\end{abstract}

Keywords: AHP, Assistant Laboratory, SPK, Selection.

\section{PENDAhUluan}

A MIK Tunas Bangsa merupakan Perguruan Tinggi di Pematangsiantar yang sedang berkembang. Dalam proses belajar mengajar, banyaknya jumlah mahasiswa dalam 1 kelas terkadang membuat Dosen kesulitan menangani dan melayani mahasiswa satu persatu, khususnya pada saat praktikum. Oleh karena itu sangat dibutuhkan seorang asisten laboratorium pada masing-masing laboratorium komputer [1]. Asisten laboratorium atau sering disebut laboran adalah orang yang membantu dosen pada saat mengajar praktikum. Seorang laboran dapat mendukung peningkatan kinerja mahasiswa pada saat praktikum di Laboratorium. Oleh karena itu kinerja laboran harus selalu optimal [2]. Dalam praktikum, asisten bertugas untuk memandu dan melayani mahasiswa secara langsung sesuai dengan kurikulum yang diterapkan [3]. Begitu pentingnya seorang asisten laboratorium dalam membantu pelaksanaan praktikum komputer di laboratorium komputer [4], sehingga pihak yayasan AMIK Tunas Bangsa Pematangsiantar dituntut agar lebih selektif dalam menerima Asisten Laboratorium yang akan bekerja pada laboratorium komputer. Salah satu cara yang efektif untuk proses seleksi dan penilaian adalah dengan menggunakan Sistem Pendukung Keputusan. Sistem Pendukung Keputusan dapat dimanfaatkan untuk membantu manusia mengambil keputusan dengan cepat, tepat dan konsisten. Sistem Pendukung Keputusan sangat tepat jika diterapkan pada permasalahan yang cukup kompleks [5], seperti pada seleksi penerimaan asisten laboratorium ini. Diharapkan dengan adanya sistem ini, akan mampu mengurangi permasalahan yang ada. Sistem ini akan melakukan perhitungan terhadap seluruh kriteria subjektif bagi calon 
asisten laboratorium hingga diharapkan laboran dengan kemampuan terbaiklah yang akan terpilih [6]. Algoritma Sistem Pendukung Keputusan yang akan diterapkan dalam penelitian ini adalah algoritma Analytical Hierarchy Process (AHP) [7]. Dasar peneliti menggunakan algoritma ini karena pada penelitian ini melibatkan beberapa kriteria dan banyak alternatif. Oleh karena itu dibutuhkan metode penelitian yang mampu mempertimbangkan aspek kualitatif dan kuantitatif, alasan lain adalah karena algoritma AHP mampu melakukan pendekatan matematis secara kompleks dan cerdas namun tetap melakukan pendekatan secara kualitatif [8]. Pada penelitian sebelumnya, [9] melakukan penelitian untuk memilih asisten laboratorium pada STMIK Palangkaraya menggunakan metode Simple Additive Weighting (SAW). Penelitian ini memiliki kelemahan yang terletak pada perhitungan nya. Perhitungan dengan menggunakan metode SAW ini menghasilkan alternatif terbaik yang terpilih berdasarkan nilai terbesar. Perhitungan akan sesuai dengan metode ini apabila kriteria yang telah ditentukan dipenuhi oleh alternatif yang terpilih. Sedangkan pada penelitian [10], membahas tentang pemilihan asisten terbaik dengan metode Topsis dan WP. Kekurangan metode ini adalah terlebih dahulu harus adanya bobot yang ditetapkan dan dihitung, selain itu konsep untuk mengukur kinerja relatif dari alternatifalternatif keputusan masih dalam bentuk matematis sederhana [11].

\section{A. Sistem Pendukung Keputusan}

Sistem Pendukung Keputusan adalah salah satu cara yang digunakan untuk membuat keputusan dengan mengorganisir informasi [12]. Pendapat lain mengatakan bahwa SPK merupakan pemodelan dan pemanipulasian data pada sistem informasi interaktif [13]. SPK digunakan untuk membantu dalam pengampilan keputusan untuk situasi yang semi terstruktur maupun yang tidak terstruktur, karena tidak seorang pun tahu secara pasti bagaimana seharusnya keputusan dibuat [14]. Pengambilan keputusan merupakan tindakan untuk mencapai tujuan atau sasaran tertentu dalam proses pemilihan alternatif. Proses pengambilan keputusan harus melalui mekanaisme tertentu dengan harapan akan menghasilkan suatu keputusan yang terbaik [15].

Ada beberapa komponen-komponen dari sistem pendukung keputusan. Antara lain : Subsistem Manajemen Data, Subsistem Manajemen Model, Subsistem Antarmuka Pengguna dan Subsistem Manajemen Berbasis Pengetahuan. Seperti ditunjukkan pada Gambar 1.

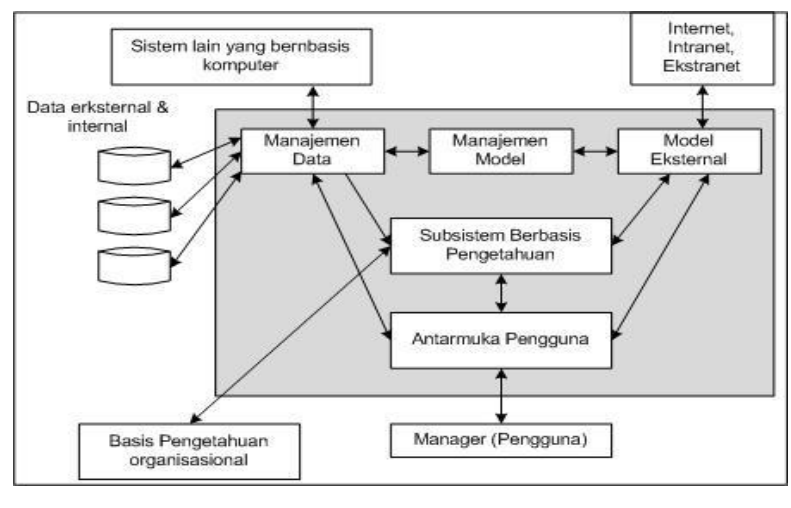

Gambar. 1 Arsitektur DSS (Decisions Support System)

\section{B. Seleksi}

Seleksi merupakan tahap akhir proses rekrutmen dimana keputusan mengenai siapa kandidat yang berhasil akan diambil [16].

\section{Asisten Laboratorium}

Asisten laboratorium adalah orang yang membantu dosen dalam memonitoring terhadap praktikan dengan cara mengontrol dan memperhatikan aktivitas praktikan dengan langsung mendatangi PC atau komputer tempat praktikan melakukan aktivitasnya [17].

\section{Analytical Hierarchy Process (AHP)}

Analytic Hierarchy Process merupakan suatu pendekatan praktis untuk memecahkan masalah keputusan yang kompleks. Pengambilan keputusan dengan algoritma AHP memungkinkan sistem untuk menyajikan hubungan hierarki antara faktor, atribut, karakteristik atau alternative dalam pengambilan keputusan [18]. Algoritma Analytical Hierarcy Process (AHP) bersifat multi kriteria karena menggunakan banyak kriteria dalam penyusunan suatu prioritas sistem pendukung keputusan. Disamping itu, metode AHP juga didasarkan pada 
proses logis dan terstruktur [19]. Ada beberapa prinsip permasalahan yang diselesaikan dengan AHP, diantaranya adalah :

1) Membuat hierarki yakni memahami sebuah sistem yang kompleks, dilakukan dengan memecah sistem tersebut menjadi elemen - elemen pendukung, menyusun elemen secara hierarki dan menggabungkannya atau mensintesiskan sistem tersebut.

2) Penilaian kriteria dan alternatif yakni kriteria dan alternatif dapat ditentukan dengan perbandingan berpasangan [20].

Ada beberapa langkah dalam perhitungan AHP antara lain:

1) Mendefinisikan masalah dan menentukan solusi yang diinginkan.

2) Membuat struktur hierarki dimulai dari tujuan umum, dilanjutkan dengan kriteria-kriteria dan alternatif pilihan.

3) Membuat matrik perbandingan berpasangan yang menggambarkan kontribusi relatif atau pengaruh setiap elemen terhadap tujuan atau kriteria yang setingkat di atasnya..

4) Menormalkan data yaitu dengan membagi nilai dari setiap elemen di dalam matrik yang berpasangan dengan nilai total dari setiap kolom

5) Menghitung nilai bobot setiap elemen (eigen vector)dengan rumus : Hitung Consistency Index (CI) dengan rumus :

dimana : $\mathrm{n}=$ banyaknya elemen

$$
\mathrm{CI}=(\lambda \text { maks-n }) / \mathrm{n}
$$

6) Mengulangi langkah 3, 4 dan 5 untuk seluruh tingkat hirarki.

7) Menghitung eigen vector dari setiap matriks perbandingan berpasangan.

8) Menguji konsistensi hirarki.

Hitung Rasio Konsistensi/Consistency Ratio (CR) dengan Rumus :

$$
\mathrm{CR}=\mathrm{CI} / \mathrm{IR}
$$

$$
\text { dimana: } \begin{aligned}
\mathrm{CR} & =\text { Consistency Ratio } \\
\mathrm{CI} & =\text { Consistensy Index } \\
\mathrm{IR} & =\text { Index Random Consistency }
\end{aligned}
$$

RI di dapat dari tabel nilai, Nilai RI dapat kita lihat pada tabel 1 berikut :

$$
\text { TABEL } 1
$$

\begin{tabular}{cc}
\multicolumn{2}{c}{ INDEKS RANDOM (IR) } \\
\hline \hline Ukuran Matrix & Nilai IR \\
\hline 1,2 & 0,00 \\
3 & 0,58 \\
4 & 0,90 \\
5 & 1,12 \\
6 & 1,24 \\
7 & 1,32 \\
8 & 1,41 \\
9 & 1,45 \\
10 & 1,49 \\
11 & 1,51 \\
12 & 1,48 \\
13 & 1,56 \\
14 & 1,57 \\
15 & 1,59 \\
\hline \hline
\end{tabular}

Memeriksa konsistensi hierarki. Jika nilainya lebih dari 10\%, maka penilaian data judgement harus diperbaiki. Namun jika rasio konsistensi (CI/IR) kurang atau sama dengan 0,1 maka hasil perhitungannya bisa dinyatakan benar [21].

\section{METODE}

Dalam seleksi penerimaan asisten laboratorium yang baik memerlukan alat bantu yang tepat, yang menggunakan komputer sebagai suatu sarana yang dapat membantu sumber daya manusia untuk mendapatkan banyak informasi secara tepat dan akurat dengan suatu metode dan perhitungan sistematis yaitu metode AHP, metode ini dapat memberikan alternatif pilihan. Pada dasarnya AHP merupakan suatu metode untuk memecahkan suatu permasalahan yang kompleks dan tidak tersetruktur ke dalam kelompoknya, mengatur kelompok tersebut ke dalam suatu hierarki. 


\section{A. Flowchart Program}

FlowchartbProgram adalah suatu simbol yang menerangkan bagaimana suatu program berjalan dari awal program ditampilkan sampai program selesai digunakan. Berikut ini adalah flowchart program yang dirancang, gambar. 3 merupakan Flowchart AHP, sedangkan Gambar. 4 adalah Flowchart Sistem :

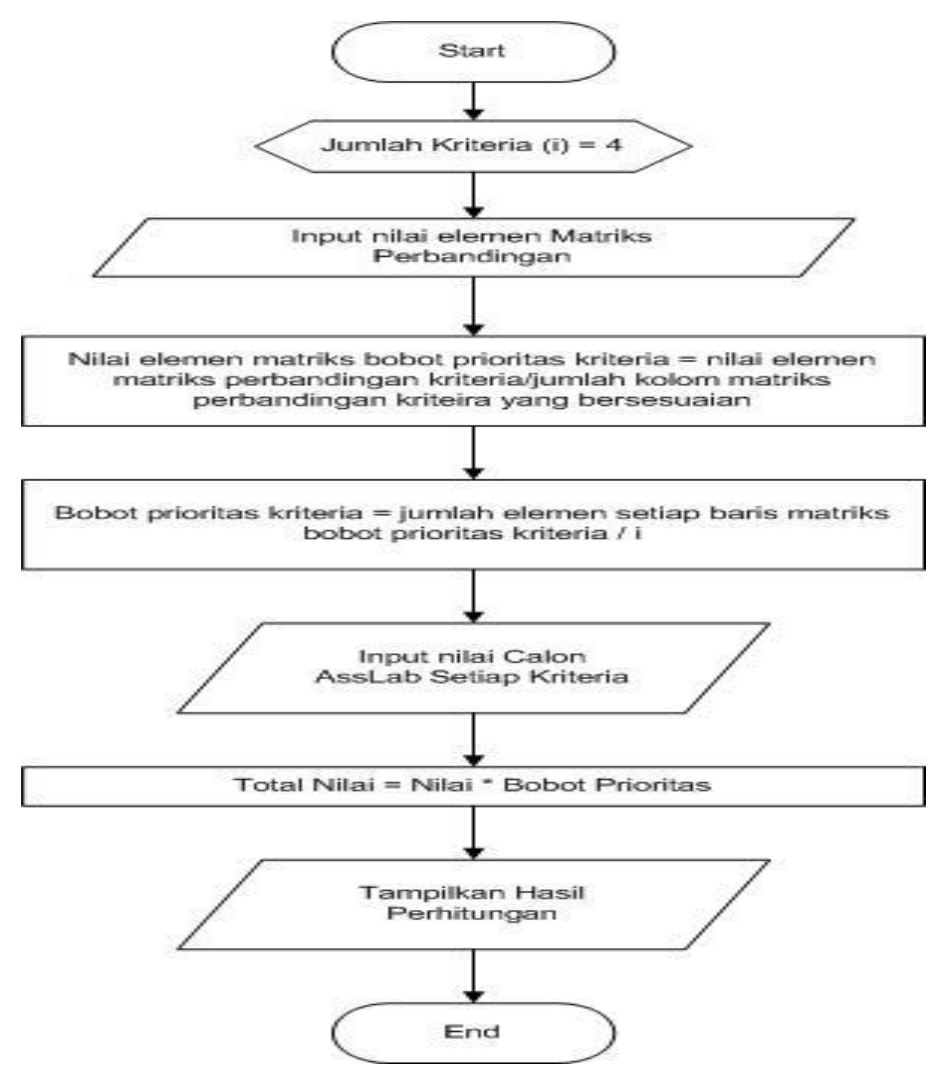

Gambar. 3. Flowchart AHP

\section{B. Flowchart Sistem}

Bagian ini memperlihatkan alur kerja atau apa yang sedang dikerjakan dalam sistem secara keseluruhan dan menjelaskan mengenai urutan dari prosedur yang terdapat pada sistem. Flowchart ini termasuk gambaran secara grafik dari urutan prosedur-prosedur yang tergabung membentuk suatu sistem. Flowchart sistem terdiri atas data yang mengalir lewat sistem dan proses yang mentransformasikan data tersebut.

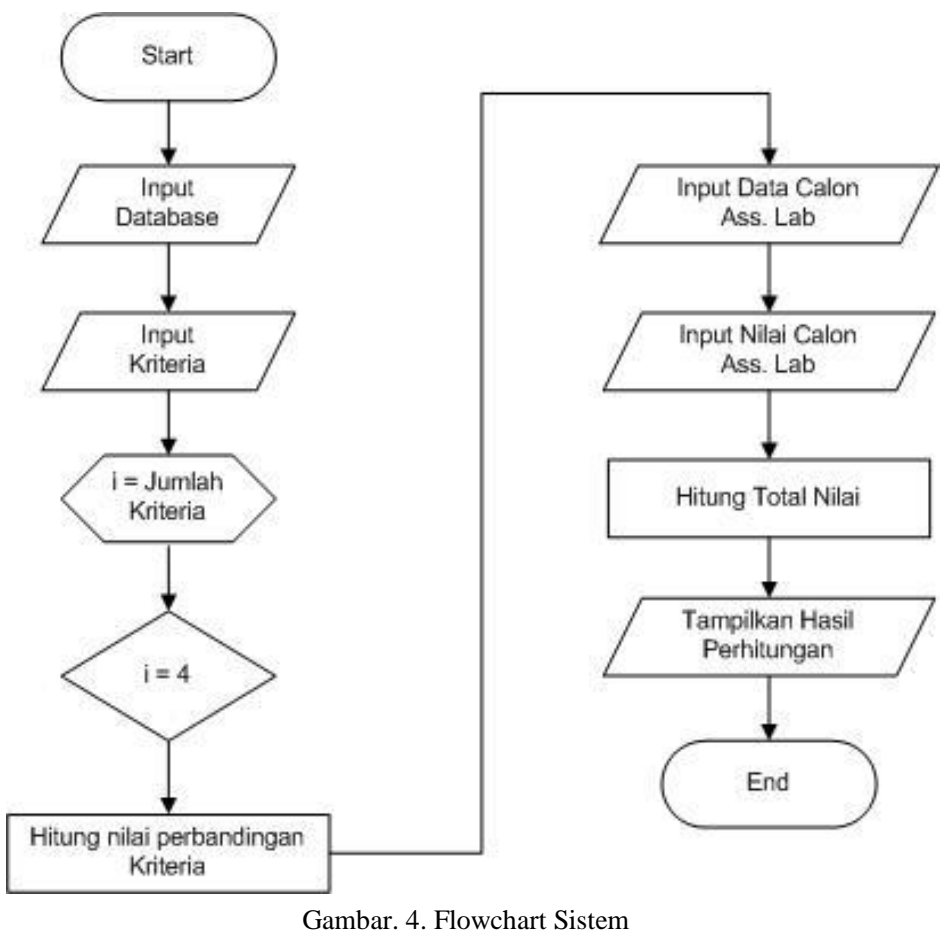


Dari gambar 4 dapat dijelaskan bahwa pertama sekali yang dilakukan adalah membuat database berdasarkan sistem yang akan dibangun, kemudian memasukkan 4 kriteria yang telah ditetapkan, yakni wawancara, ujian tertulis ujian praktek dan IPK. Kemudian keempat kriteria tersebut di bandingkan satu per satu. Setelah itu akan dimasukkan data calon asisten laboratorium beserta nilai yang diperoleh. Selanjutnya akan dilakukan proses perhitungan total nilai dari masing-masing calon asisten laboratorium yang kemudian akan menghasilkan perhitungan secara keseluruhan sehingga akhirnya akan diperoleh siapa saja calon terbaik yang terpilih.

\section{HASIL}

Untuk memperoleh hasil penelitian dengan menggunakan metode AHP ini adalah dengan melakukan langkahlangkah perhitungan sebagai berikut :

1) Menentukan jenis-jenis kriteria yang akan dipertimbangkan. Dalam sistem pendukung keputusan seleksi penerimaan asisten laboratorium pada AMIK Tunas Bangsa Pematangsiantar, instansi tersebut menetapkan kriteria-kriteria yang digunakan sebagai acuan dalam pengambilan keputusan yaitu Wawancara, Ujian Tertulis, Ujian Praktek, IPK. Kemudian keempat kriteria tersebut di bandingkan satu per satu, yang dalam istilah AHP disebut dengan pair-wise comparation.

2) Menyusun hierarki dimana diawali dengan tujuan dan kemudian kriteria pada tingkat bawah. Urutan hierarki tersebut dapat dilihat pada gambar 2 .

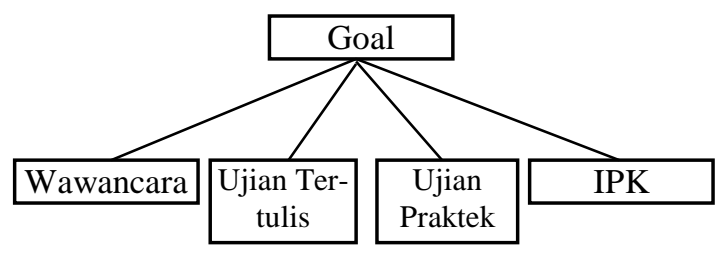

Gambar. 2. Urutan Hierarki Sistem

3) Setelah disusun hierarki diatas langkah selanjutnya yaitu melakukan perhitungan konsistensi perbandingan tiap-tiap kriteria berdasarkan tingkat kebutuhan ataupun tingkat kepentingan antara kriteria yang satu denga kriteria yang lainnya dengan menggunakan metode AHP. Nilai diagonal matriks untuk perbandingan suatu elemen-elemen dengan elemen itu sendiri diisi dengan nilai (1) sedangkan isi nilai perbandingan antar 1 sampai dengan 9 kebalikannya. Perbandingan antara kriteria yang satu dengan yang lainnya dapat dilihat pada tabel 2 berikut ini :

TABEL 2

MATRIKS PERBANDINGAN KRITERIA

\begin{tabular}{lcccc}
\hline \hline \multicolumn{1}{c}{ Kriteria } & Wawancara & Ujian Tertulis & Ujian Praktek & IPK \\
\hline Wawancara & 1 & 1 & 0.5 & 0.5 \\
Ujian Tertulis & 1 & 1 & 0.5 & 0.33 \\
Ujian Praktek & 2 & 2 & 1 & 0.5 \\
IPK & 2 & 3 & 2 & 1 \\
Jumlah & 6 & 7 & 4 & 2.33 \\
\hline \hline
\end{tabular}

4) Menghitung Matriks Prioritas Kriteria. Pada tahap ini akan dicari prioritas kriteria untuk nantinya menentukan apakah nilai dimasukkan dalam matriks yang sesuai. Nilai pada matriks diperoleh dari membagi nilai kolom baris dengan jumlah kolom. Prioritas diperoleh dengan cara membagikan jumlah tiap baris dengan jumlah matriks. Dapat dilihat pada tabel 3 berikut ini :

TABEL 3

MATRIKS PRIORITAS PERBANDINGAN KRITERIA

\begin{tabular}{lcccccc}
\hline \hline \multicolumn{1}{c}{ Kriteria } & Wawancara & Ujian Tertulis & Ujian Praktek & IPK & Jumlah & Prioritas \\
\hline Wawancara & 0.17 & 0.14 & 0.13 & 0.21 & $\mathbf{0 . 6 5}$ & $\mathbf{0 . 1 6}$ \\
Ujian Tertulis & 0.17 & 0.14 & 0.13 & 0.14 & $\mathbf{0 . 5 8}$ & $\mathbf{0 . 1 5}$ \\
Ujian Praktek & 0.33 & 0.29 & 0.21 & 0.21 & $\mathbf{1 . 0 8}$ & $\mathbf{0 . 2 7}$ \\
IPK & 0.33 & 0.43 & 0.43 & 0.43 & $\mathbf{1 . 6 9}$ & $\mathbf{0 . 4 2}$ \\
\hline \hline
\end{tabular}

5) Menghitung matriks penjumlahan kriteria. Nilai pada matriks diperoleh dengan cara mengalikan nilai kolom baris pada tabel matriks perbandingan kriteria dengan prioritas masing-masing kriteria. Dapat dilihat pada tabel 4 .

TABEL 4

MATRIKS PENJUMLAHAN TIAP BARIS

\begin{tabular}{cccccc}
\hline \hline Kriteria & Wawancara & Ujian Tertulis & Ujian Praktek & IPK & Jumlah \\
\hline Wawancara & 0.16 & 0.16 & 0.08 & 0.08 & 0.48 \\
\hline
\end{tabular}




\begin{tabular}{lccccc}
\hline \hline \multicolumn{1}{c}{ Kriteria } & Wawancara & Ujian Tertulis & Ujian Praktek & IPK & Jumlah \\
\hline Ujian Tertulis & 0.15 & 0.15 & 0.08 & 0.05 & 0.43 \\
Ujian Praktek & 0.54 & 0.54 & 0.27 & 0.14 & 1.49 \\
IPK & 0.84 & 1.26 & 0.84 & 0.42 & 3.36 \\
\hline \hline
\end{tabular}

6) Menghitung matriks rasio konsistensi.

TABEL 5 MATRIKS RASIO KONSISTENSI

\begin{tabular}{lccc}
\hline \hline & Jumlah Baris & Prioritas & Hasil \\
\hline Wawancara & 0.48 & 0.16 & 0.64 \\
Ujian Tertulis & 0.43 & 0.15 & 0.58 \\
Ujian Praktek & 1.49 & 0.27 & 1.76 \\
IPK & 3.36 & 0.42 & 3.78 \\
\hline \hline
\end{tabular}

Jumlah rasio $=6.76$

Jumlah Kriteria $(\mathrm{n})=4$

$\lambda$ maks $=$ Jumlah Rasio $/ \mathrm{n}=6.76 / 4=1.69$

$\mathrm{CI}=(\lambda$ maks-n $) /(\mathrm{n}-1)=(1.69-4) /(4-1)=-0.77$

$\mathrm{CR}=\mathrm{CI} / \mathrm{RI}=-0.77 / 0.90=-0.86$

Oleh karena nilai CR (Consistency Ratio) dari kriteria < 0.1, maka rasio konsistensi dari perhitungan tersebut dapat Diterima.

7) Setelah mendapatkan nilai bobot prioritas maka dapat mencari total nilai dengan cara nilai setiap kriteria calon asisten laboratorium dikalikan dengan nilai bobot prioritas yang bersesuaian. Misal data nilai pada tabel dibawah ini :

TABEL 6

NILAI CALON ASISTEN LABORATORIUM

\begin{tabular}{cccccc}
\hline \hline NIM & Nama & Wawancara & Ujian Tertulis & Ujian Praktek & IPK \\
\hline 201201030237 & Budiman & 78 & 80 & 83 & 3,40 \\
201301030024 & Marzan & 60 & 65 & 70 & 2,99 \\
\hline \hline
\end{tabular}

Total Nilai $(201201030237)=(78 \times 0.16)+(80 \times 0.15)+(83 \times 0.27)+(3.40 \times 0.42)=48,32$

Total Nilai $(201201030024)=(60 \times 0.16)+(65 \times 0.15)+(70 \times 0.27)+(2.99 \times 0.42)=39,51$

TABEL 7

TOTAL NILAI CALON ASISTEN LABORATORIUM

\begin{tabular}{ccccccc}
\hline \hline NIM & Nama & IPK & Wawancara & Ujian Tertulis & Ujian Praktek & Total Nilai \\
\hline 201201030237 & Budiman & 3.40 & 78 & 80 & 83 & 48,32 \\
201301030024 & Marzan & 2.99 & 60 & 65 & 70 & 39,51 \\
\hline \hline
\end{tabular}

\section{PEMBAHASAN}

Pembahasan dan implementasi dari Seleksi penerimaan asisten laboratorium pada AMIK-STIKOM Tunas bangsa Pematangsiantar dibangun menggunakan pemrograman Web. Secara umum dapat dilihat pada gambar 5, gambar 6, gambar 7 berikut ini :

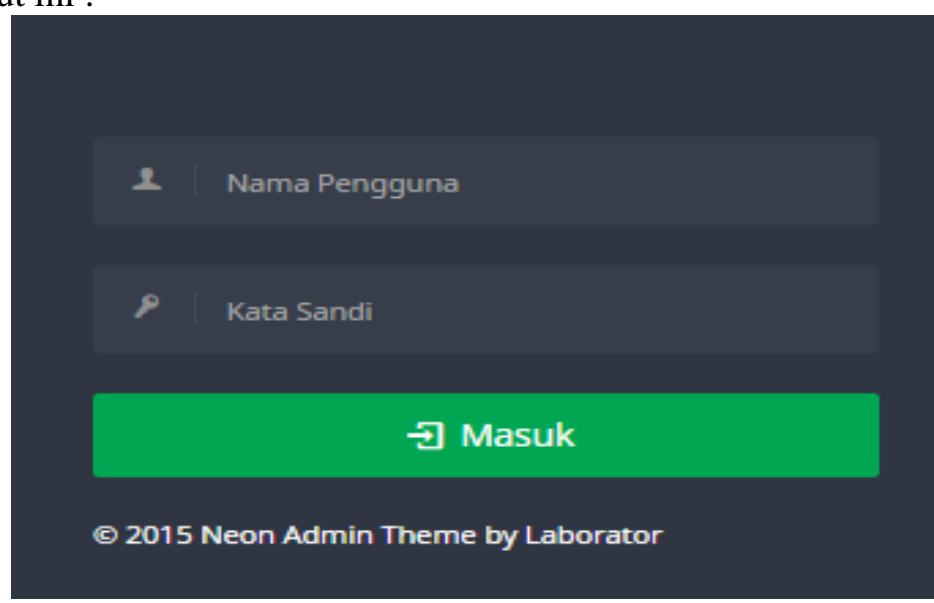

Gambar. 5. Halaman Login 
Halaman login berfungsi sebagai tahap awal agar bisa masuk kedalam sistem. Halaman login merupakan halaman untuk menginput username dan password agar dapat masuk ke halaman utama

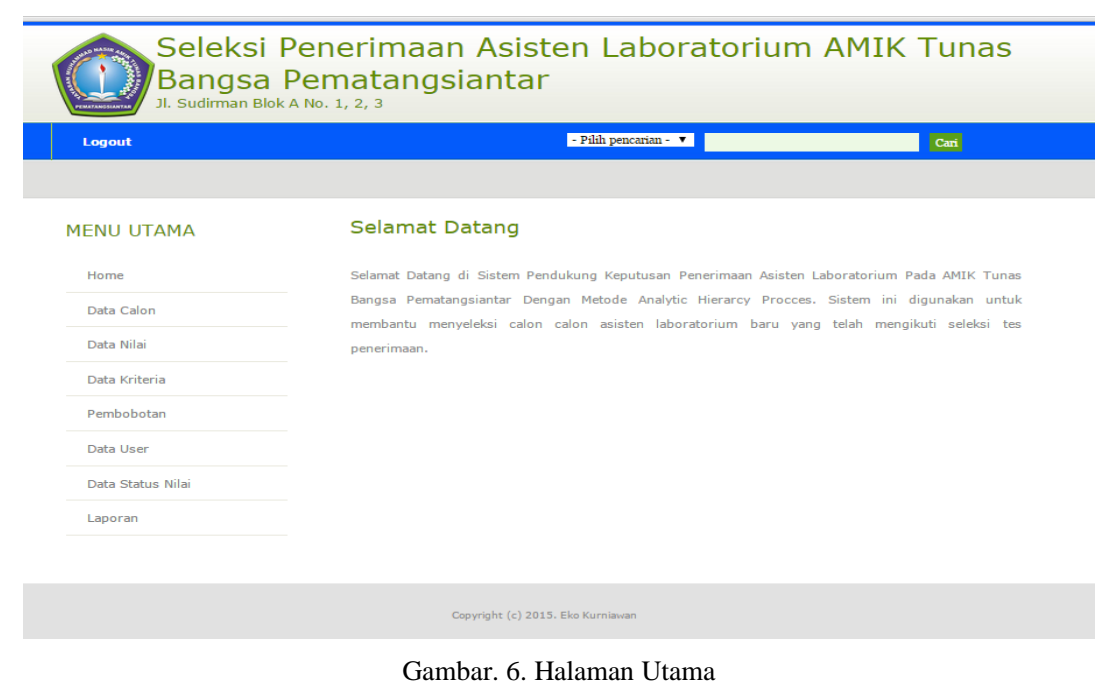

Halaman Utama akan tampil apabila pengguna sistem berhasil login.

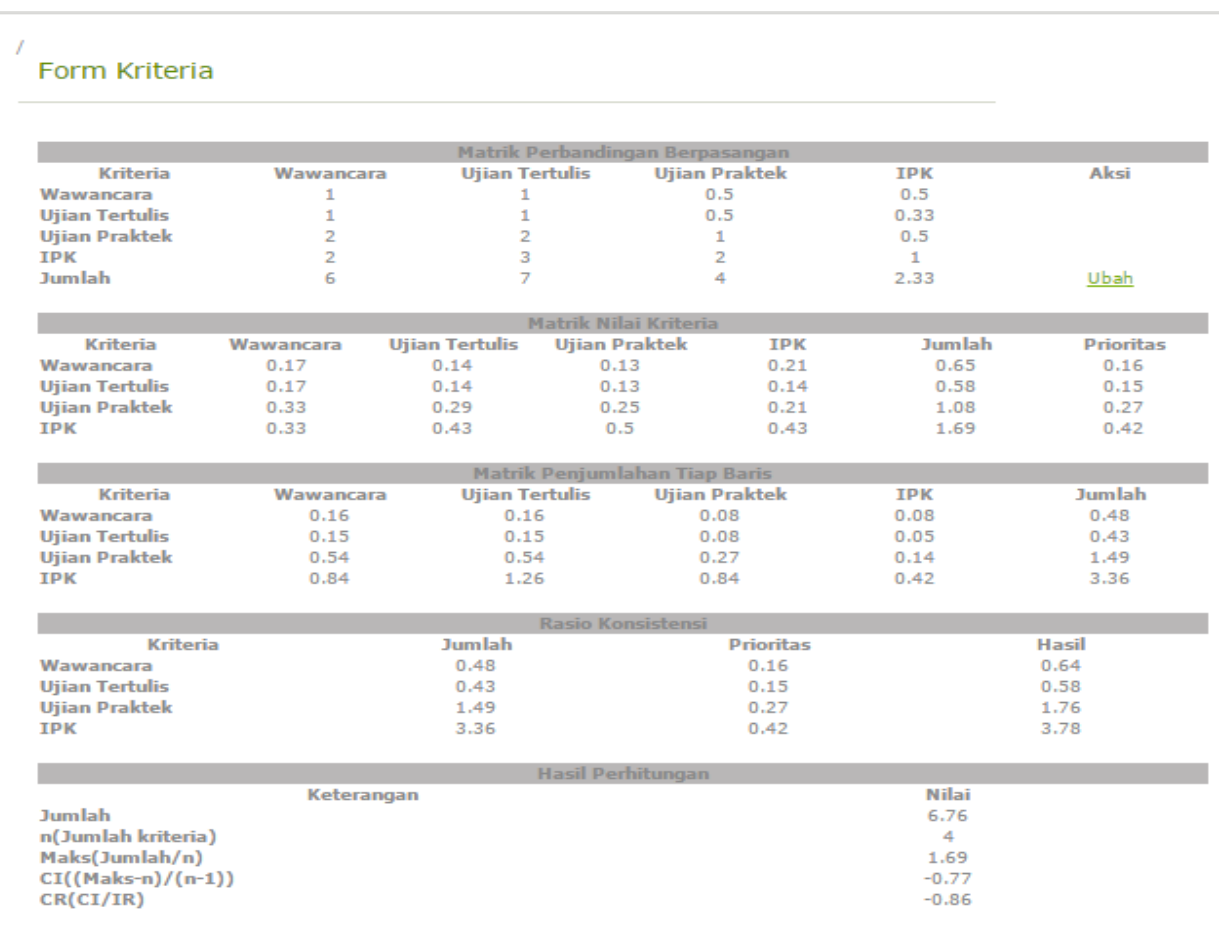

Gambar. 7. Halaman Pembobotan Kriteria

Halaman Pembobotan Kriteria akan tampil apabila pengguna memilih menu Pembobotan dari Halaman Utama. Halaman ini berisi data pembobotan dan kriteria dari calon asisten laboratorium yang telah diuji.

\section{Data Nilai}

\begin{tabular}{|c|c|c|c|c|c|c|c|}
\hline \multicolumn{8}{|c|}{ LIST DATA NILAI } \\
\hline NIM & IPK & Wawancara & Ujian Tertu & ian Praktek & Hasil & Keterangan & Aksi \\
\hline 1201301030025 & $3.5(\mathrm{~A})$ & 78 (B) & 80 (B) & 90 (A) & 48.78 & Diterima & Ubah | Hapus \\
\hline 2201301030270 & $3(\mathrm{~B})$ & $70(C)$ & $70(C)$ & 70 (C) & 40.6 & Diterima & Ubah $\mid \overline{\text { Hapus }}$ \\
\hline 3201401030253 & $2.9(\mathrm{C})$ & $68(C)$ & $65(C)$ & 69 (C) & 39.26 & Ditolak & $\frac{\text { Ubah }}{\text { Tambah }}$ \\
\hline
\end{tabular}


Halaman Nilai akan tampil apabila pengguna memilih menu Data status nilai dari Halaman Utama. Halaman ini berisi data hasil pengujian secara keseluruhan. Dari halaman ini dapat diketahui siapa calon asisten laboratorium yang terpilih dengan nilai terbaik.

\section{SIMPULAN DAN SARAN}

Dari penjelasan dan penjabaran sebelumnya, maka dapat diambil beberapa kesimpulan antara lain :

1) Metode AHP dapat digunakan untuk penyeleksian penerimaan asisten laboratorium pada AMIK-STIKOM Tunas Bangsa Pematangsiantar. Dengan perhitungan menggunakan metode AHP ini, akan diperoleh calon asisten laboratorium terbaik yang terpilih berdasarkan kriteria-kriteria yang telah ditentukan.

2) Sistem ini dapat digunakan pimpinan sebagai dasar pengambilan keputusan dalam menentukan calon asisten laboratorium yang layak diterima bekerja pada perguruan tinggi.

Adapun saran dari penulis agar penelitan ini lebih baik kedepannya antara lain :

1) Penelitian ini hendaknya dikembangkan dengan menggunakan metode-metode lain selain AHP.

2) Menambahkan variabel lain dalam pengelompokkan dan penentuan calon asisten laboratorium.

\section{REFERENSI}

[1] A. Wanto, "Analisis Penerapan Fuzzy Inference System (FIS) Dengan Metode Mamdani Pada Sistem Prediksi Mahasiswa Non Aktif (Studi Kasus : AMIK Tunas Bangsa Pematangsiantar)," Seminar Nasional Inovasi Dan Teknologi Informasi (SNITI 3), no. November, pp. 393-400, 2016.

[2] E. Lestari, "Kolaborasi Metode Saw Dan Ahp Untuk Sistem Pendukung Keputusan Penilaian Kinerja Asisten Laboratorium," Jurnal Sistem Informasi (JSI), vol. 9, no. 1, pp. 1204-1215, 2017.

[3] A. Suryana, E. Yulianto, and K. D. Pratama, "Perancangan Sistem Pendukung Keputusan Penilaian Prestasi Pegawai Menggunakan Metode SAW, AHP, dan TOPSIS," Jurnal Ilmiah Teknologi Informasi Terapan, vol. III, no. 2, pp. 130-139, 2017.

[4] Rahimullaily and L. Maltaf, "Penerapan Multimetode Berbasis Matriks Pada Seleksi Penerimaan Calon Asisten Labor," Jurnal Derivat, vol. 4, no. 1, pp. 37-51, 2017.

[5] A. Fachrial, Z. Arifin, and D. M. Khairina, "Sistem Pendukung Keputusan Penentuan Lokasi Pembuangan Akhir Sampah Kota Samarinda Metode Simple Aditive Weighting Berbasis Desktop,” Seminar Ilmu Komputer dan Teknologi Informasi, vol. 2, no. 1, pp. 142-145, 2017.

[6] D. A. Kristiyanti, "Sistem Pendukung Keputusan Seleksi Karyawan Untuk Jabatan Tertentu Dengan Pendekatan Analisa Gap Profile Matching," Jurnal Paradigma, vol. 19, no. 1, pp. 20-29, 2017.

[7] G. P. Sanyoto, R. I. Handayani, and E. Widanengsih, "Sistem Pendukung Keputusan Pemilihan Laptop Untuk Kebutuhan Operasional Dengan Metode AHP ( Studi Kasus : Direktorat Pembinaan Kursus Dan Pelatihan Kemdikbud)," Jurnal Pilar Nusa Mandiri, vol. 13, no. 2, pp. 167-174, 2017.

[8] H. Magdalena and H. Santoso, "Studi Faktor Penilaian Plagiat Menggunakan Analytical Hierarchy Process : Sebuah Studi Kasus Kualitatif," Jurnal Sisfo, vol. 6, no. 2, pp. 183-198, 2017.

[9] Rosmiati, "Sistem Pendukung Keputusan Pemilihan Asisten Laboratorium Menggunakan Metode Simple Additive Weighting (SAW)," Jurnal Saintekom, vol. 6, no. 1, pp. 16-26, 2016.

[10] E. G. Wahyuni, N. Khairunnisa, F. Abriyani, N. F. Muchlis, and M. Ulfa, "Sistem Pendukung Keputusan Pemilihan Asisten Terbaik Dengan Metode Topsis dan WP," Jurnal Teknoin, vol. 22, no. 2, pp. 93-100, 2017.

[11] H. Purwanto, "Sistem Penunjang Keputusan Pemilihan Notebook Dengan Menggunakan Metode TOPSIS," Jurnal Ilmu Pengetahuan dan Teknologi Komputer, vol. 2, no. 2, pp. 55-59, 2017.

[12] S. Sundari, A. Wanto, Saifullah, and I. Gunawan, "Sistem Pendukung Keputusan Dengan Menggunakan Metode Electre Dalam Merekomendasikan Dosen Berprestasi Bidang Ilmu Komputer ( Study Kasus di AMIK \& STIKOM Tunas Bangsa )," Seminar Nasional Multi Disiplin Ilmu, pp. 1-6, 2017.

[13] A. Wanto and H. Damanik, "Analisis Penerapan Sistem Pendukung Keputusan Terhadap Seleksi Penerima Beasiswa BBM ( Bantuan Belajar Mahasiswa ) Pada Perguruan Tinggi Menggunakan Metode Simple Additive Weighting ( SAW ) ( Studi Kasus: AMIK Tunas Bangsa Pematangsiantar )," Seminar Nasional Rekayasa (SNTR) II, no. November, pp. 323-333, 2015.

[14] R. I. Handayani, "Sistem Pendukung kepUtusan Pemilihan Karyawan Berprestasi Dengan Metode Profile Matching pada PT . Sarana Inti Persada ( SIP )," Jurnal Pilar Nusa Mandiri Volume, vol. 13, no. 1, pp. 28-34, 2017.

[15] D. F. Shiddieq and E. Septyan, "Analisis Perbandingan Metode AHP Dan saw Dalam Penilaian Kinerja Karyawan (Studi Kasus Di PT. Grafindo Media pratama Bandung)," Jurnal LPKIA, vol. 1, no. 1, 2017.

[16] H. S. Wijaya and S. Kempa, "Proses Rekrutmen dan Seleksi Pada PT . PACIFIC Jaya Persada," Jurnal AGORA, vol. 5, no. 1, 2017.

[17] S. H. Mansyur and I. R. Duwila, "Perancangan Aplikasi Monitoring Pc Berbasis Desktop Pada Program Studi Teknik Informatika Fakultas Ilmu Komputer UMI," ILKOM Jurnal Ilmiah, vol. 9, no. 2, pp. 196-202, 2017.

[18] Muhammad, Anwar, Syarifuddin, and Amrullah, "Aplikasi Pendukung keputusan Pemilihan Bakal Calon Anggota legislatif oleh Partai Politik di Indonesia dengan Metode AHP," Industrial Engineering Journal, vol. 5, no. 2, pp. 4-10, 2016.

[19] M. Widyasuti, A. Wanto, D. Hartama, and E. Purwanto, "Rekomendasi Penjualan Aksesoris Handphone Menggunakan Metode Analitycal Hierarchy Process ( AHP )," Konferensi Nasional Teknologi Informasi dan Komputer (KOMIK), vol. I, no. 1, pp. 27-32, 2017.

[20] M. Ade, I. Suryani, Z. Arifin, and H. R. Hatta, "Pemilihan Paket Wisata Menggunakan Metode Analytical Hierarchy Process ( AHP )," Jurnal Informatika Mulawarman, vol. 12, no. 2, pp. 64-68, 2017.

[21] N. Lestari, R. Handayani, and Y. J. SY, "Implementasi Sistem Pendukung Keputusan Dalam Pemberian Bantuan Kepada Masyarakat Desa," Jurnal Sains dan Informatika, vol. 3, no. 12, pp. 61-71, 2017. 